\title{
Vanishing lung syndrome
}

\author{
Jing Wang PhD(c), Wei Liu PhD MD
}

\begin{abstract}
A 19-year-old woman was admitted to the emergency room with acute pleuritic chest pain. She had no significant medical history, but was a current smoker. Computed tomography of the chest revealed a giant bulla occupying more than three-quarters of the left hemithorax, compressing the residual lung and displacing the mediastinum toward the opposite side (Figure 1). The images were consistent with vanishing lung syndrome (VLS). At thoracotomy, a giant bulla (at least $20 \mathrm{~cm}$ in diameter) was present in the left upper lobe. Bullectomy was performed without incident, allowing re-expansion of the underlying lung (Figure 2). Pathological examination showed an enlarged airspace with paraseptal emphysema on the margin and infiltration of inflammatory cells.
\end{abstract}

\section{KEY LEARNING POINTS}

- VLS is characterized by giant bullae that compress the underlying lung and cause it to seemingly disappear. The bullae are frequently asymmetric or unilateral, and limited to the upper lobes $(1,2)$.

- VLS usually occurs in younger patients and may present with dyspnea, hemoptysis or chest pain (3).

- Paraseptal emphysema underlies most cases of VLS (2), which must be differentiated from other congenital and acquired cystic diseases of the lung.

- Differentiating VLS from pneumothorax is very important. On chest radiography, a pneumothorax will usually cause the lung parenchyma to collapse into a clump toward the hilum. In VLS, the compressed lung usually falls away from the hilum down toward the cardiophrenic angle. Computed tomography often shows fine septations within the bulla or a thin, barely perceptible wall; these may be quite difficult to identify on a standard chest radiograph.

- Treatment is surgical bullectomy (either by thoracotomy or thoracoscopy) and is indicated to relieve pulmonary compression and eliminate the risk of pneumothorax. In the unlikely event of acute distention causing respiratory failure and circulatory collapse, urgent intracavitary drainage should be considered.

\section{REFERENCES}

1. Roberts L, Putman CE, Chen JTT, Goodman LR, Ravin CE.

Vanishing lung syndrome: Upper lobe bullous pneumopathy.

Revista interamericana de radiología 1987;12:249-55.

2. Stern EJ, Webb WR, Weinacker A, Müller NL. Idiopathic giant bullous emphysema (vanishing lung syndrome): Imaging findings in nine patients. Am J Roentgenol 1994;162:279-82.

3. Sharma N, Justaniah AM, Kanne JP, Gurney JW, Mohammed TL. Vanishing lung syndrome (giant bullous emphysema): CT findings in 7 patients and a literature review. J Thorac Imaging 2009;24:227-30.

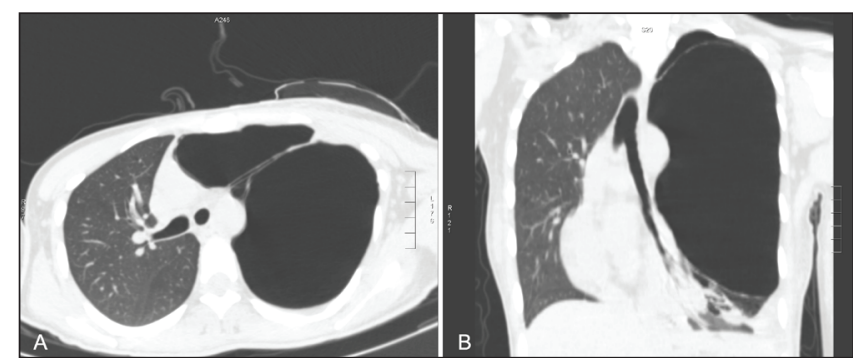

Figure 1) Chest computed tomography of a 19-year-old woman with extensive bullous disease. Axial (A) and coronal (B) views show a giant bulla occupying more than three-quarters of the left hemithorax. The mediastinum is displaced to right and the left lung parenchyma is compressed to the extent that it is barely visible

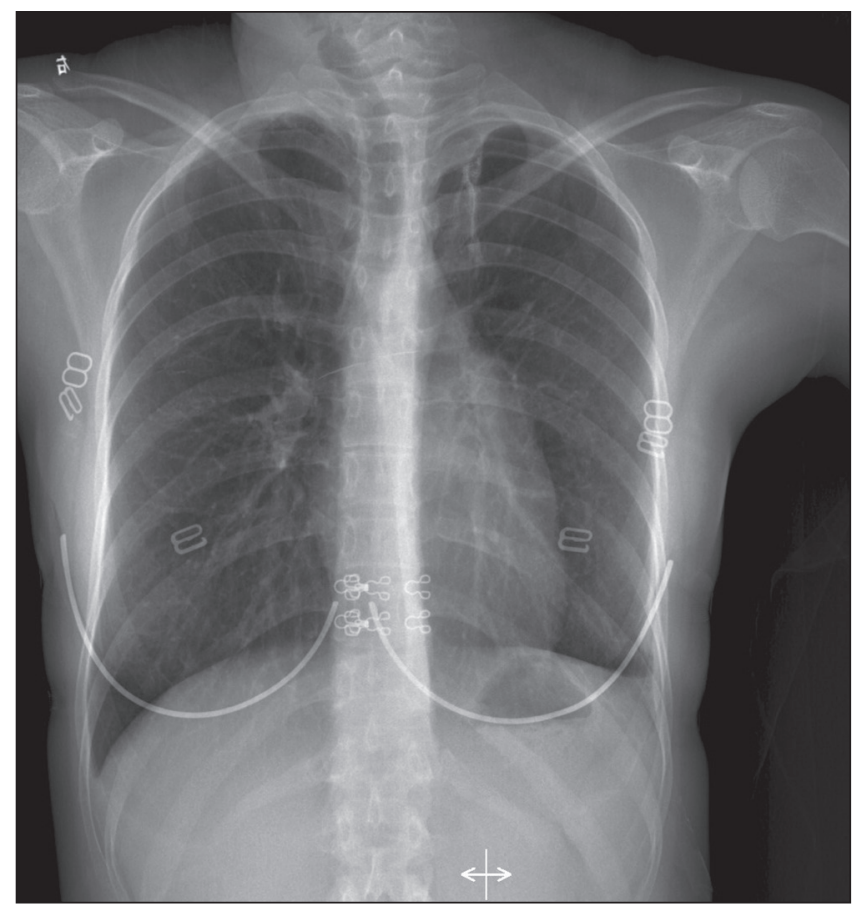

Figure 2) Chest $x$-ray seven days after surgery showing re-expansion of the left lung

The 'Images in Respiratory Medicine' section of the Canadian Respiratory Journal aims to highlight the importance of visual interpretation, whether physiological, radiological, bronchoscopic, surgical/thorascopic or histological, in the diagnosis of chest diseases. Submissions should exemplify a classic, particularly dramatic or intriguing presentation of a disease while offering an important educational message to the reader (insightful diagnostic pearls or differential diagnosis, etc). This section is not intended to be a vehicle for publication of case reports (see the Clinical-Pathologic Conferences for case-based leaning series).

Department of Radiology, Bethune First Hospital, Jilin University, Changchun, China

Correspondence: Dr Wei Liu, Department of Thoracic Surgery, Bethune First Hospital, Jilin University, No. 71 Xinmin Street, Changchun 130021, China. Telephone 86-431-88782973, fax 86-431-88782733, e-mail davidliuw@hotmail.com 


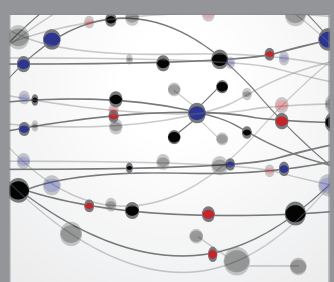

The Scientific World Journal
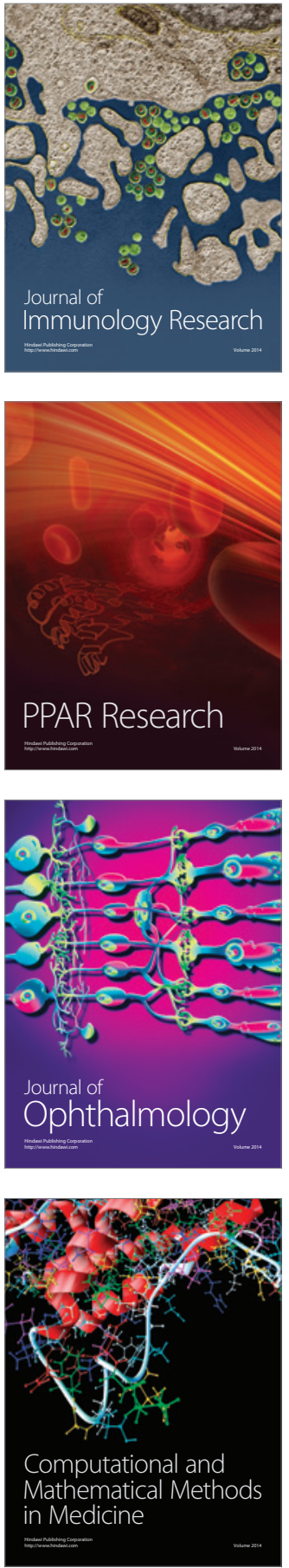

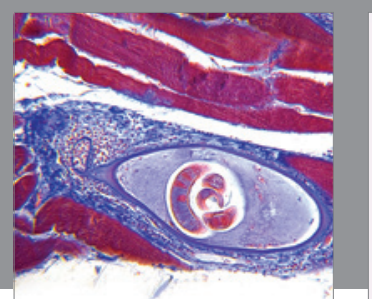

Gastroenterology Research and Practice

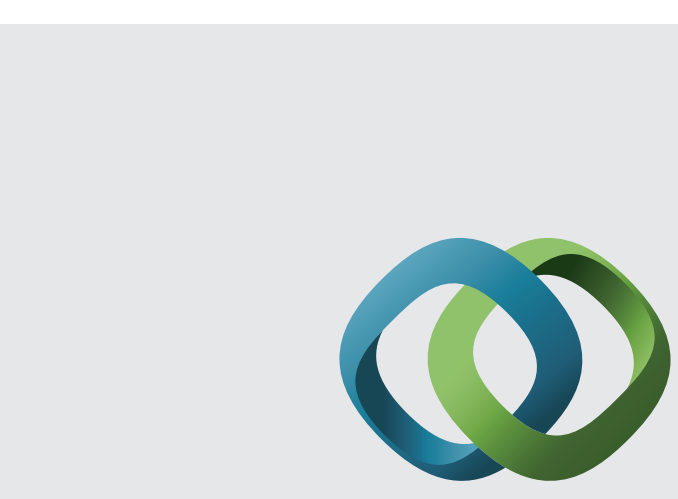

\section{Hindawi}

Submit your manuscripts at

http://www.hindawi.com
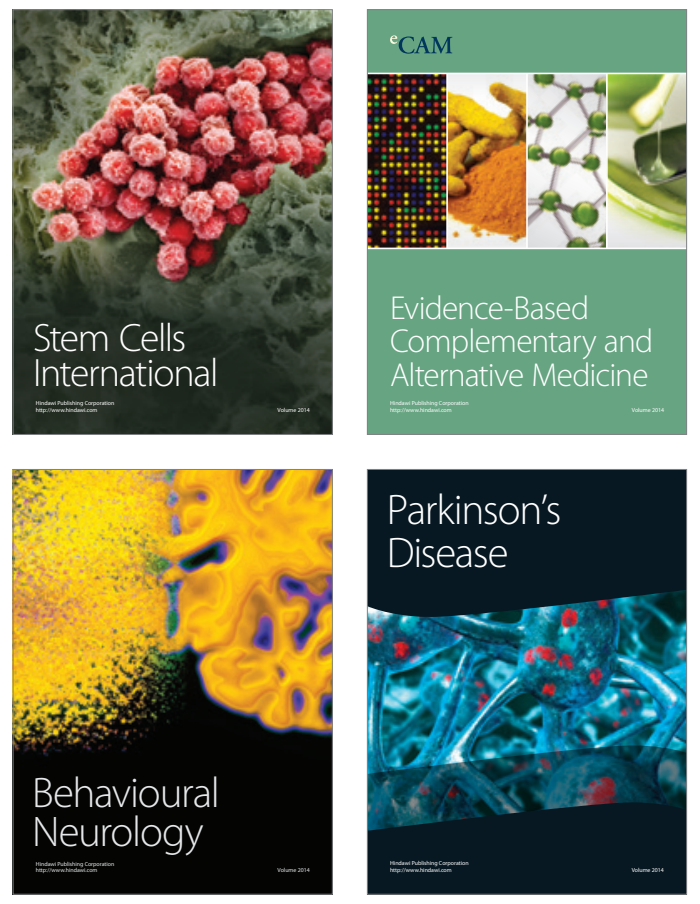
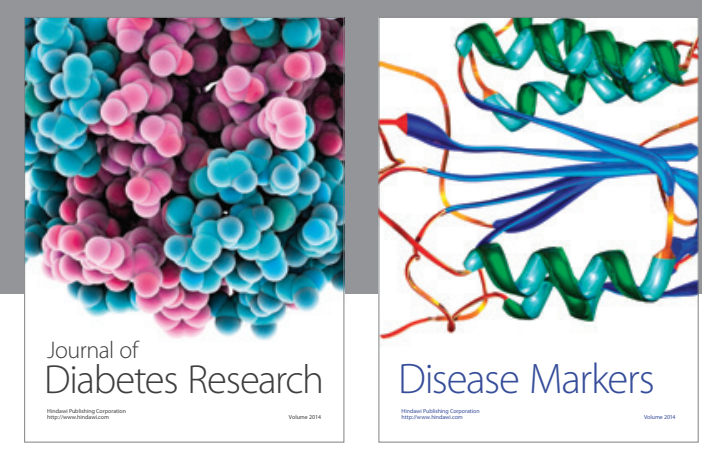

Disease Markers
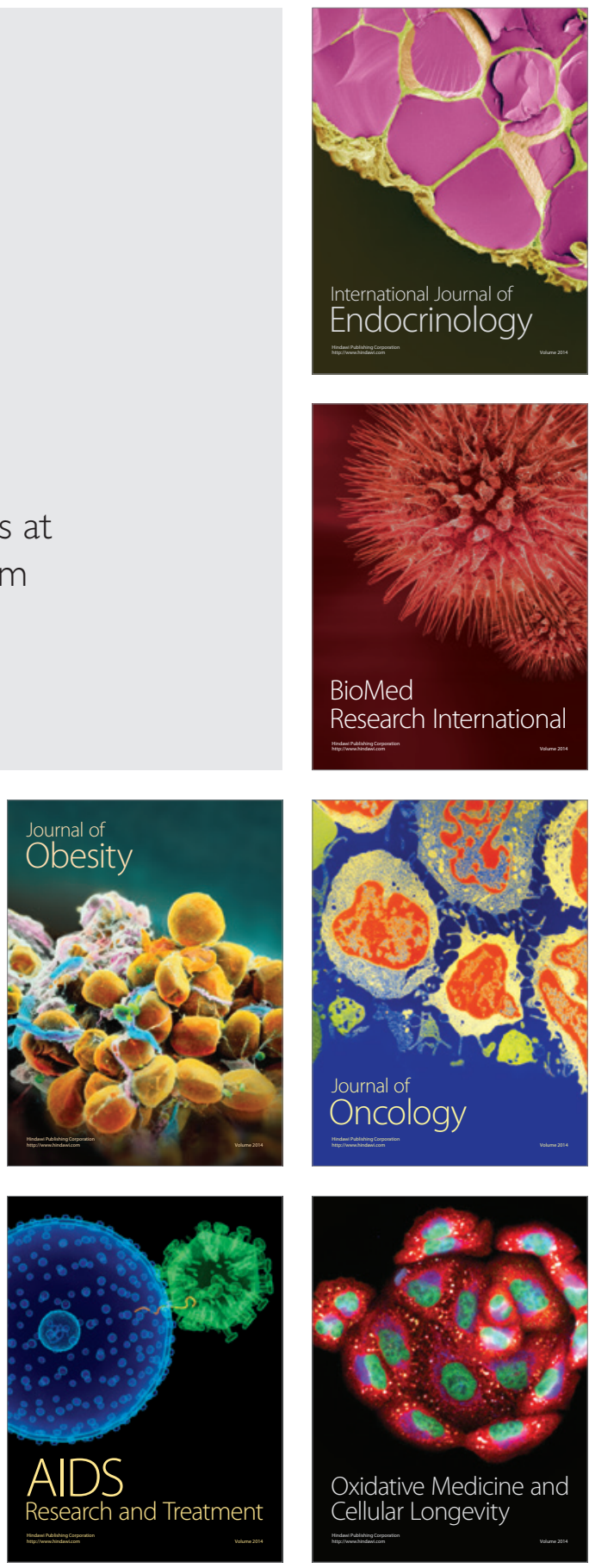